\title{
CFD Model Study of a New Four-Port Submerged Entry Nozzle for Decreasing the Turbulence in Slab Casting Mold
}

\author{
Debasish Chatterjee \\ Department of Metallurgy \& Materials Engineering, Indian Institute of Technology, Roorkee 247667, Uttarakhand, India \\ Correspondence should be addressed to Debasish Chatterjee; deb100dmt@gmail.com
}

Received 5 September 2013; Accepted 12 October 2013

Academic Editors: Y. Hao, Y.-d. Wang, and T. Yue

Copyright (C) 2013 Debasish Chatterjee. This is an open access article distributed under the Creative Commons Attribution License, which permits unrestricted use, distribution, and reproduction in any medium, provided the original work is properly cited.

\begin{abstract}
In recent years, the continuous casting process in which molten metal is constantly cast into semifinished shapes has been widely adopted in the steel and nonferrous metal producing industry, mainly due to its economic advantages associated with increased yields and the elimination of intermediate processing steps. Turbulent flow in submerged entrance nozzle and mold of continuous casting is associated with costly failure such as the entrainment of slag inclusions and the formation of surface defects. A number of previously studies have analyzed the flow. A CFD model study has done to decrease the turbulence within the mold by developing a 4-port submerged entry nozzle in comparison with conventional 2-port submerged entry nozzle. VOF (volume of fluid) simulation study has been done to find out the effect of turbulence within mold on slag metal interaction, level fluctuation, and risk of breakout. In all the cases the performance of new 4-port SEN over 2-port SEN has been compared by plotting graph.
\end{abstract}

\section{Introduction}

Steel maker around the world is emphasized to increase the production rate to cope with the global demand of steel in coming decade. Simultaneously the supply of quality steel is demanding by customer. But to meet this stringent demand is very difficult as production machine has certain drawbacks and limitations. One of these drawbacks is creation of turbulence within mold during casting of steel at high casting speed. The submerged entry nozzle (SEN) with two bifurcated ports is commonly applied in slab continuous casting. As the source of the flow, the SEN decides on the steel flow pattern in the mold. For unreasonable nozzle design, impingement of hot liquid metal with high momentum against the solidifying shell can contribute to shell thinning and costly breakout as well as large surface fluctuation [1]. Scientists have been interested in the fluid flow that is observed in the mold during continuous casting because the flow pattern affects the inner and the surface quality of the steel slab to a great extent. Figure 1(a) shows the basic phenomenon produced in the mold during the continuous casting. The flow pattern depends on the structure of the submerged entry nozzle (SEN) and other relative parameters. On the one hand, a calm and smooth mold level assists the uniform formation of the strand shell in circumferential direction and reduces the thermomechanical stresses in the strand shell. It also allows the homogeneous intake of casting powder into the lubrication gap between the strand shell and the mold wall and this, in turn, is essential for optimum lubrication and homogeneous heat transfer [2]. Several authors have studied fluid flow. Both physical and mathematical models have been developed to access the flow pattern and the surface waves. Turbulent flow and heat transfer coupled with solidification in slab continuous casting, particle image velocimetry (PIV) technique mold has been studied [1,2]. Turbulent flow in SEN by large eddy simulation, turbulent flow in mold during ladle change operation, decreasing turbulent flow by use of EMBR, effect of submergence depth of SEN on mold turbulence, and so forth have been studied by many researchers in past [1-8]. The current research is to decrease the turbulence in the mold to increase the product quality and indirectly increasing the yield of caster without hampering the normal casting process.

\section{Present Work}

Turbulent flow in submerged entrance nozzle and mold of continuous casting is associated with costly failure such as the entrainment of slag inclusions and the formation of surface 


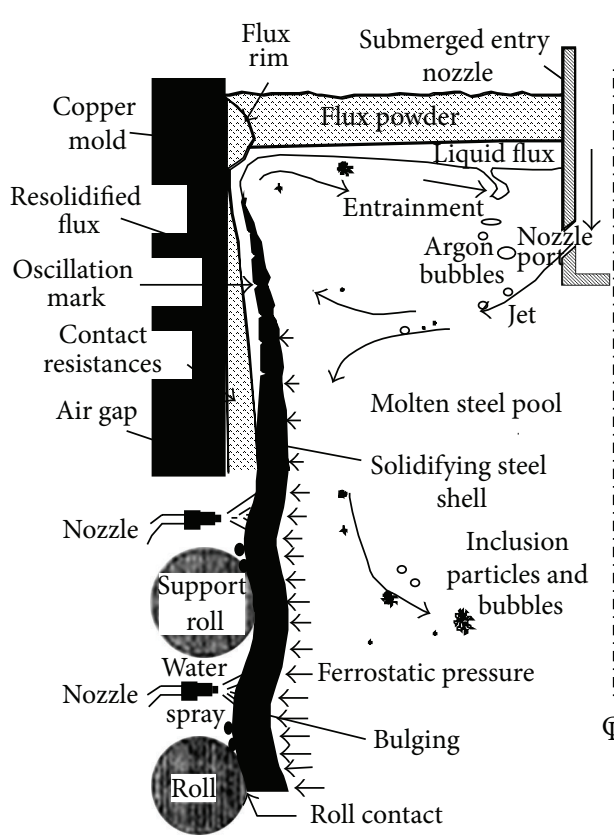

(a)

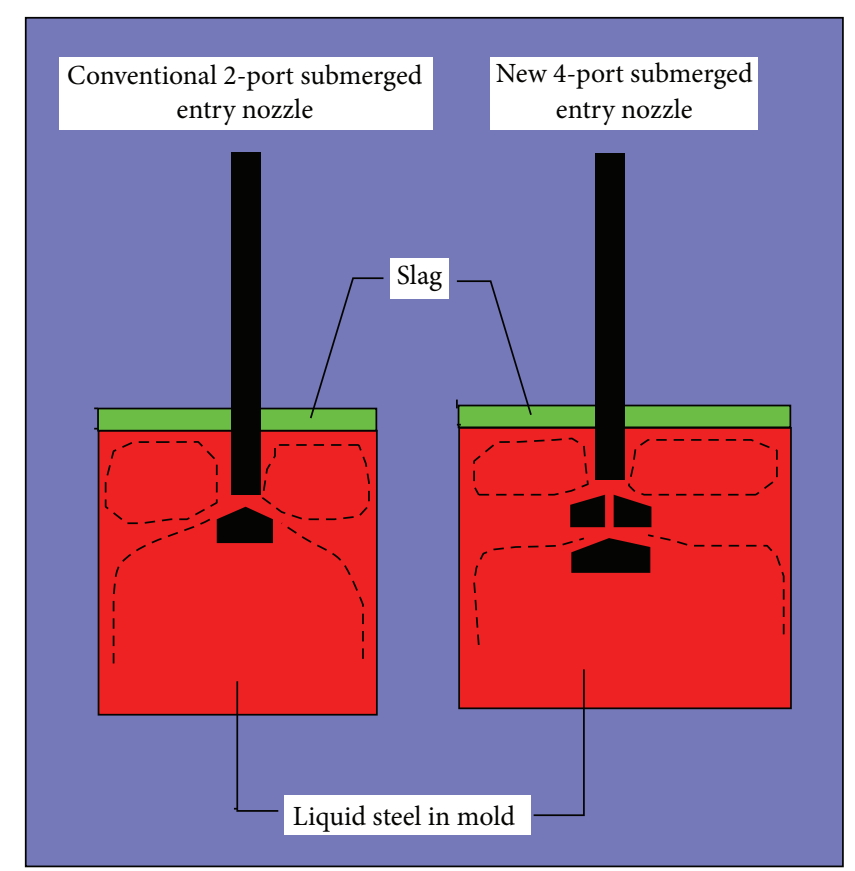

(b)

FIGURE 1: (a) Schematic of flow phenomena in mold of continuous casting [2] and (b) schematic of 2-port and new 4-port SEN.

defects [3]. The mold is one of the most important components of a continuous caster. It is known that the quality of metal castings is affected by a number of parameters directly related to the turbulent transport processes taking place within the mold. An understanding of transport processes in the liquid metal pool is of particular importance because it can be used in controlling the growth rate of the solidifying shell, thus affecting the microstructure of the final casting. The transport processes also control the formation of various defects, which can hamper subsequent processing. Examples of defects formed in this region are macrosegregation, surface irregularities, such as cold folding and oscillation marks, and more serious defects such as longitudinal or transverse cracks. A more catastrophic problem, which may occur, is "breakout," where the shell ruptures and molten metal is discharged in an uncontrolled manner [4].

The present work has developed a new 4-port submerged entry nozzle over conventional 2-port submerged entry nozzle which is schematically shown in Figure 1(b). The objective is to lower the turbulence within the mold. The conventional bifurcated SEN has 2 holes symmetrically opposite position embedded in a vertical cylindrical nozzle. The 4-port nozzle has 4 holes symmetrically opposite position embedded in the upper and lower part of a vertically cylindrical nozzle. The two parts are connected each other by a vertical cylindrical hole which has less diameter than the diameter of the main central nozzle. When the same volume of fluid will eject from 4 holes (each hole diameter of 4-port SEN = each hole diameter of 2-port SEN), it will experienced a less velocity compare to 2-port SEN. In the present work computational fluid dynamics software Fluent has been used to study the turbulence phenomena of 4-port nozzle and it has been compared with 2-port SEN.

\section{Results and Discussion}

3.1. Velocity Profile. The contour of velocity has been plotted in Figures 2(a) and 2(b) for 2-port and 4-port submerged entry nozzle, respectively. A $1000 \mathrm{~mm}$ wide, $220 \mathrm{~mm}$ thick, and $900 \mathrm{~mm}$ long mold was used for simulation. The submerged entry nozzle having internal diameter $60 \mathrm{~mm}$ and port of $40 \mathrm{~mm}$ diameter was used. It was immersed $150 \mathrm{~mm}$ in the liquid. The simulating liquid was water whose kinematic viscosity is equal to liquid steel. The casting speed was taken $1.6 \mathrm{~m} / \mathrm{min}$. the velocity of flowing water through the submerged entry nozzle was $2 \mathrm{~m} / \mathrm{sec}$. When the fluid impinges on the dome of the SEN, it flows through bifurcated nozzle for 2-port condition. The fluid is hitting the mold side wall and creating an upper and downward motion. It is creating turbulence within the mold. The boundary condition used for this simulation was velocity inlet at the upper entry of SEN. The lower part of the mold was outflow boundary condition as amount of liquid through the SEN to the mold will be equal to exact amount of metal solidified as going to out from old as semifinished product. The other side of the mold used as wall boundary condition. The velocity has been plotted along $X$ and $Z$ direction in Figures 2(c) and 2(d). It has been found out that the velocity of flowing fluid for 2-port SEN has high value as compared to 4-port SEN. It means that 4-port nozzle will provide less turbulence in mold compare to 2-port nozzle.

3.2. Slag Metal Interaction in Mold. The VOF (volume of fluid) simulation has been done to simulate the slag metal interaction within the mold. Here 4 phases have been used. The phases are air (primary phase), slag (ice water mixture), steel (water has been used as simulating material), and tracer (water). At the onset the slag was stagnant. After flowing 

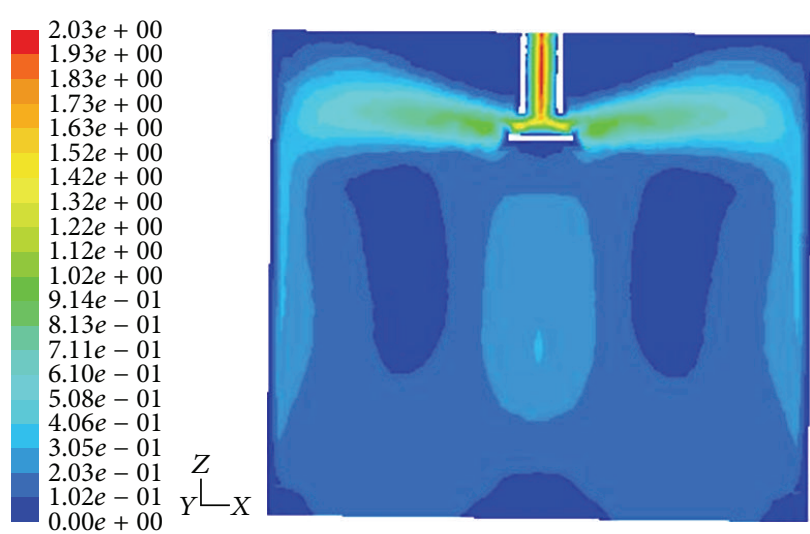

(a)

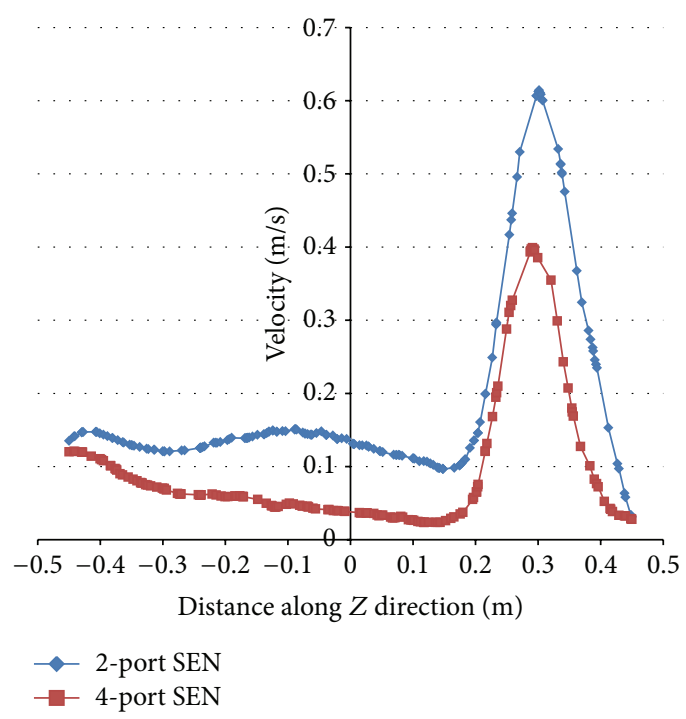

(c)
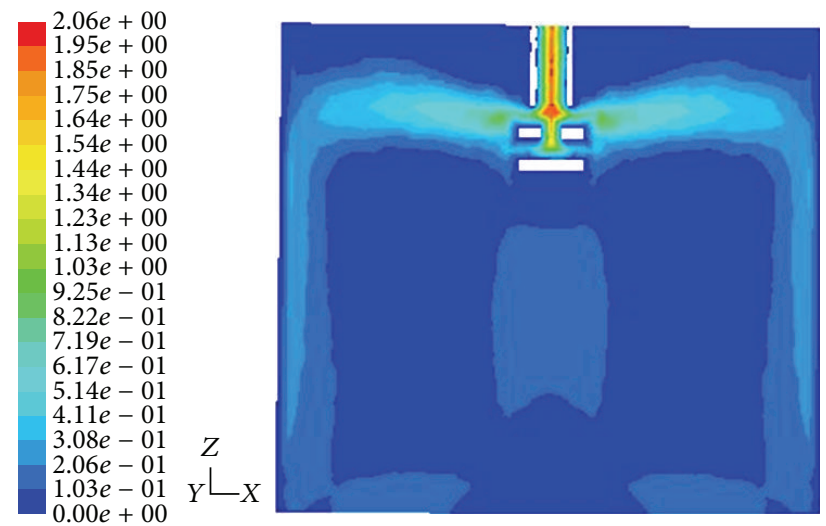

(b)

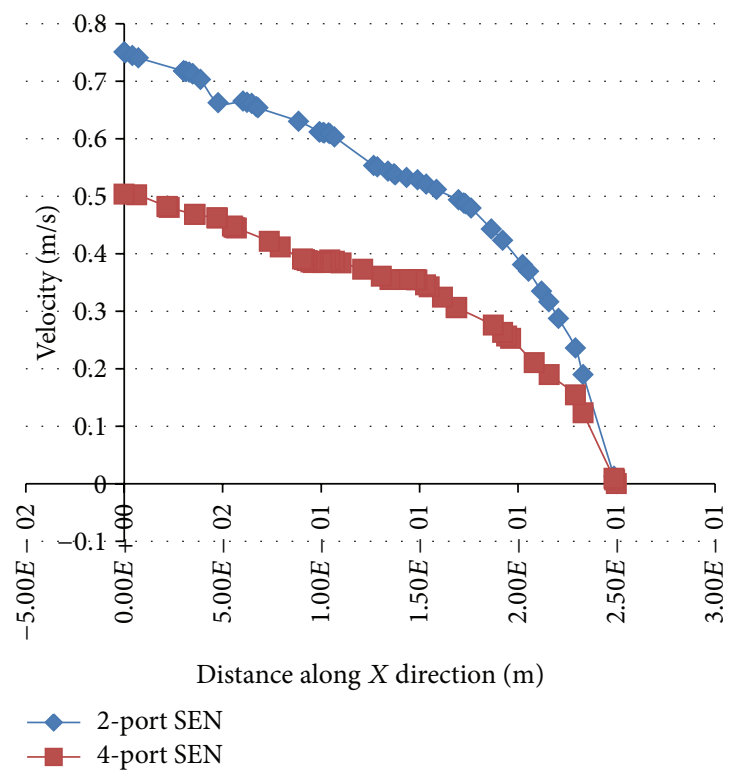

(d)

Figure 2: (a) Velocity contour of 2-ports SEN, (b) velocity contour of 4-port SEN, and (c) velocity plot along Z direction, and (d) velocity plot along $X$ direction.

fluid through the mold upper slag phase shape was changed. For 2-port SEN (submerged entry nozzle), the shape was much distorted as compared to 4-port SEN. It has been demonstrated in Figures 3(a), 3(b), 3(e), and 3(f).

Slag eye has great effect on the quality of cast steel. As mold is the last metallurgical reactor, slag has significant role to supply quality of steel to customer. Due to opening of slag eye reoxidation of the melt takes place within the mold which ultimately causes severe sliver defects after hot rolling. Slag act as a layer which capture the inclusion generated by previous subsequent processes. But due to turbulence and overflow, slag cannot remove the inclusion from the upcoming stream of steel. Instead it increases the number of large size ( $>50$ micro meter) inclusions within the mold. As the slag eye opened for 2-port nozzle, so it has detrimental effect on the steel. But compared to 4-port nozzle, no opening of slag eye was observed in the computational simulation results. It has been shown in the Figures 3(c) and 3(g).
Figures $3(\mathrm{~d})$ and $3(\mathrm{~h})$ show volume fraction of the incoming fluid within the mold after certain time elapsed. Not only that it showed the tracking of fluid within the mold. The fluid which ejected from the submerged entry nozzle impacted with mold side wall with a high speed. It creates an upper and lower flow of thin layer of fluid along the side wall of the mold. For the case of 2-port nozzle as compared to 4-port nozzle, the impinging velocity was high which is evidence from the large amount of fluid was climbing along the side wall of the mold. When this upward flow fluid interacts with the slag layer, an opening of slag eye was formed. Beside this, the mold that contains 2-port nozzle shows the presence of scattered volume of tracer fluid in the mold. It is not observed for the case of mold containing 4-port nozzle. It signifies that 2-port SEN creates more turbulence in the mold as compared to 4-port SEN.

3.3. Surface Fluctuation. Higher casting speed of liquid steel has been an important requirement in the steel-making 


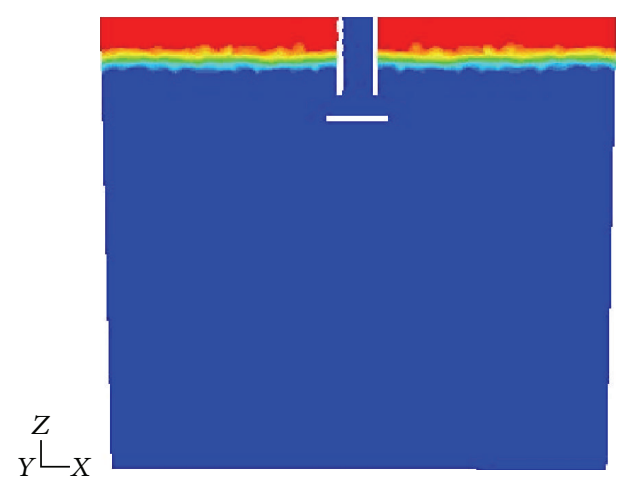

(a)

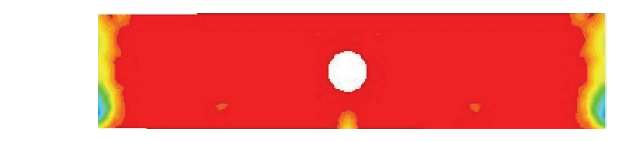

${ }^{Y}{ }^{L} X$

(c)

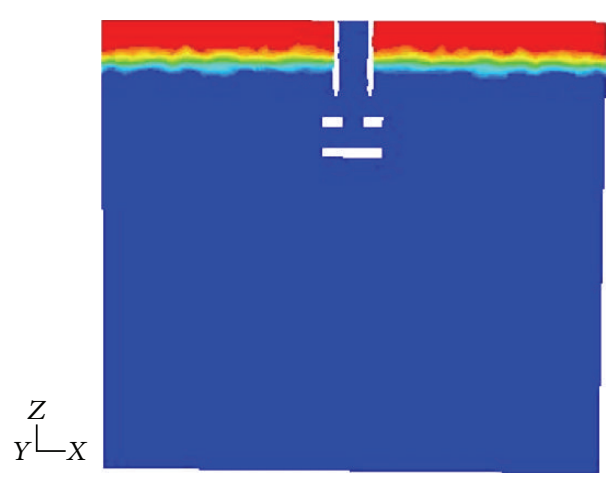

(e)

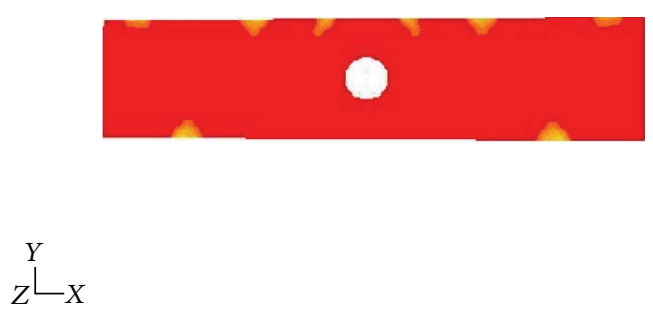

(g)

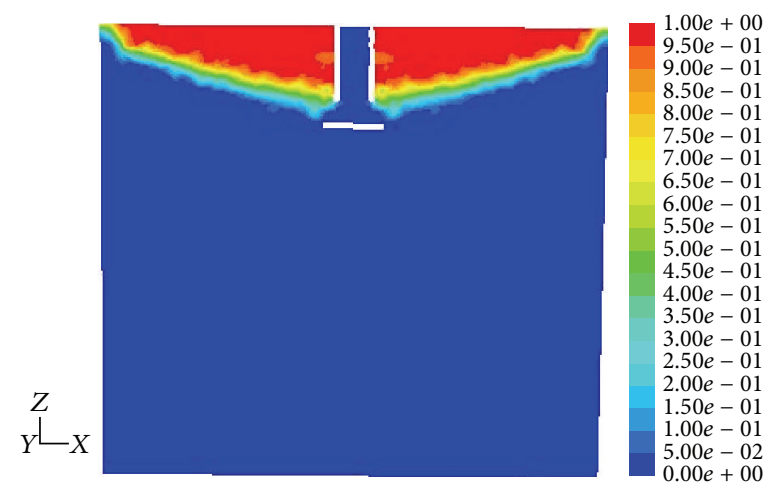

(b)

$1.00 e+00$
$9.50 e-01$
$9.00 e-01$
$8.50 e-01$
$8.00 e-01$
$7.50 e-01$
$7.00 e-01$
$6.50 e-01$
$6.00 e-01$
$5.50 e-01$
$5.00 e-01$
$4.50 e-01$
$4.00 e-01$
$3.50 e-01$
$3.00 e-01$
$2.50 e-01$
$2.00 e-01$
$1.50 e-01$
$1.00 e-01$
$5.00 e-02$
$0.00 e+00$
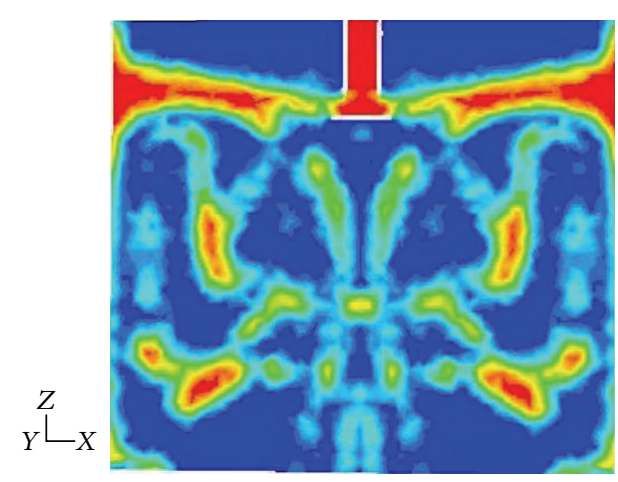

$1.00 e+00$
$9.50 e-01$
$9.00 e-01$
$8.50 e-01$
$8.00 e-01$
$7.50 e-01$
$7.00 e-01$
$6.50 e-01$
$6.00 e-01$
$5.50 e-01$
$5.00 e-01$
$4.50 e-01$
$4.00 e-01$
$3.50 e-01$
$3.00 e-01$
$2.50 e-01$
$2.00 e-01$
$1.50 e-01$
$1.00 e-01$
$5.00 e-02$
$0.00 e+00$

(d)
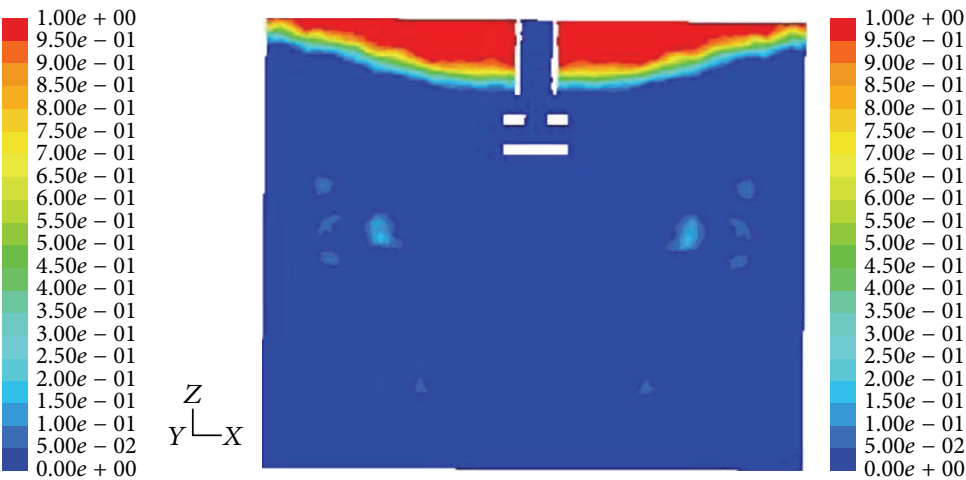

(f)
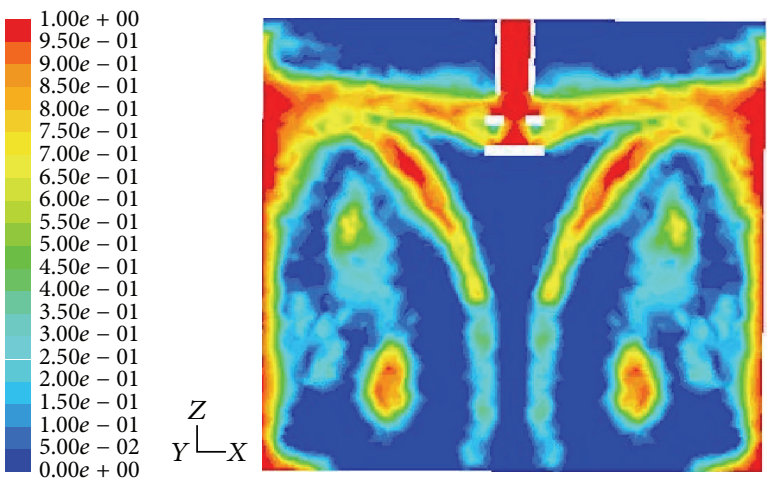

$1.00 e+00$
$9.50 e-01$
$9.00 e-01$
$8.50 e-01$
$8.00 e-01$
$7.50 e-01$
$7.00 e-01$
$6.50 e-01$
$6.00 e-01$
$5.50 e-01$
$5.00 e-01$
$4.50 e-01$
$4.00 e-01$
$3.50 e-01$
$3.00 e-01$
$2.50 e-01$
$2.00 e-01$
$1.50 e-01$
$1.00 e-01$
$5.00 e-02$
$0.00 e+00$

(h)

Figure 3: 2-port SEN: (a) slag volume before flow, (b) after flow, (c) slag eye, and (d) volume fraction of incoming fluid. 4-port SEN: (e) slag volume before flow, (f) after flow, (g) no slag eye, and (h) volume fraction of incoming fluid. 


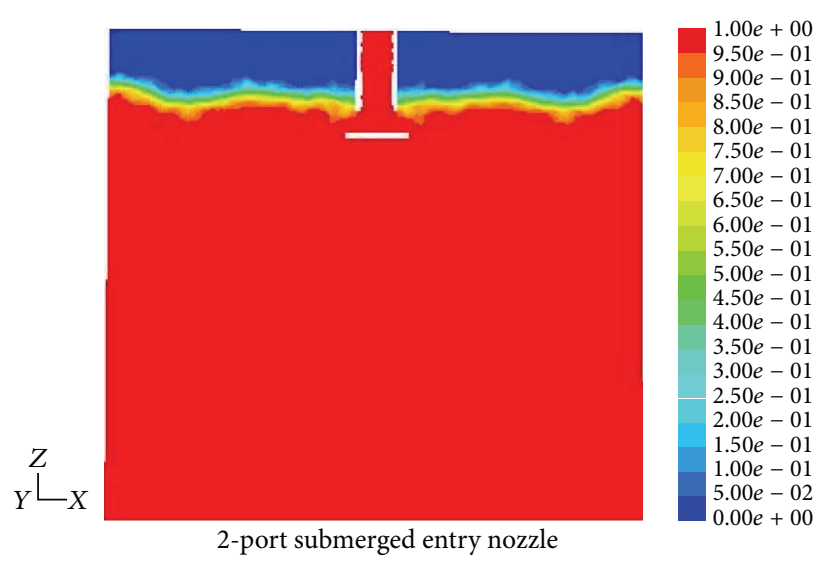

(a)

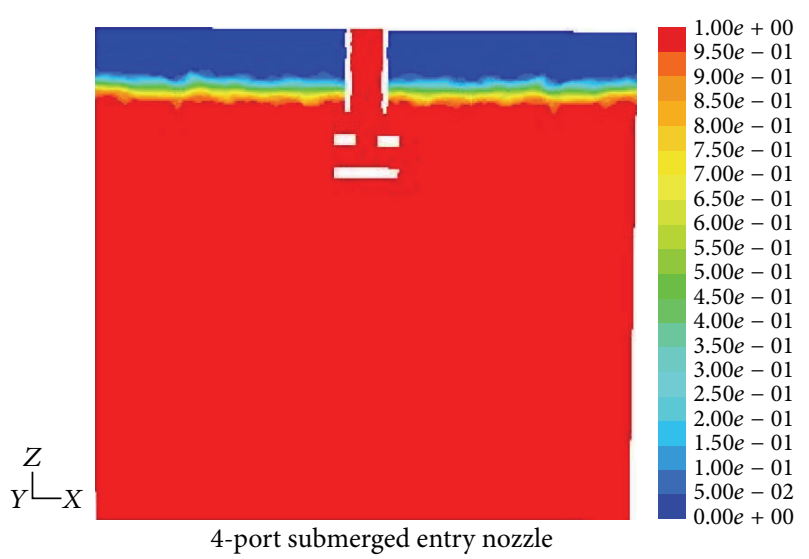

(b)

FIGURE 4: (a) Level fluctuation of 2-port SEN and (b) level fluctuation of 4-port SEN.

industry. In a continuous slab caster, a higher casting speed may lead to several problems such as higher meniscus turbulence and frequent vortex formation, due to which there is entrainment of slag into the liquid steel. This may lead to a compromise with the quality of steel produced. Thus, modeling and CFD analysis of free-surface fluctuation become necessary for design of submerged entry nozzles [5]. There is a close correlation between the fluctuation of the mold steel level and the occurrence of surface defects of final products: it is considered that when the mold steel level fluctuates significantly, casting powder and other impurities floating on the surface of molten steel are entrapped in steel, and they appear in the form of surface defects of steel sheet products during rolling. To prevent this, mold level control is designed so as to minimize the fluctuation of the mold steel level.

A new 4-port submerged entry nozzle has been designed over conventional 2-port submerged entry nozzle. The VOF (volume of fluid) simulation has been done to capture the level fluctuation within the mold. It is shown in Figures 4(a) and $4(\mathrm{~b})$. Here only 2 phases have been simulated. One phase is air which is primary phase and another phase is water which is secondary phase. After certain time interval (6$7 \mathrm{sec}$ ), it was observed from simulation plot that the surface of the 2-port mold was much more zigzag. But after the same time interval, 4-port SEN mold surface was quiescent and no distortion on the surface was observed. The upper blue colour was air phase and the red colour was water phase. So it is concluded that the 4-port nozzle will help to produce much cleaner steel as compared to 2-port nozzle. The entrainment of slag within the melt in the mold will be less for 4-port submerged entry nozzle as compared to 2-port submerged entry nozzle.

3.4. Risk of Breakout. In the continuous casing production, breakout accident is the most typical and greatest damage industrial accident, especially, sticking type breakout. It is reported that the loss of once reached up to several million money. Breakout phenomenon is caused by various factors

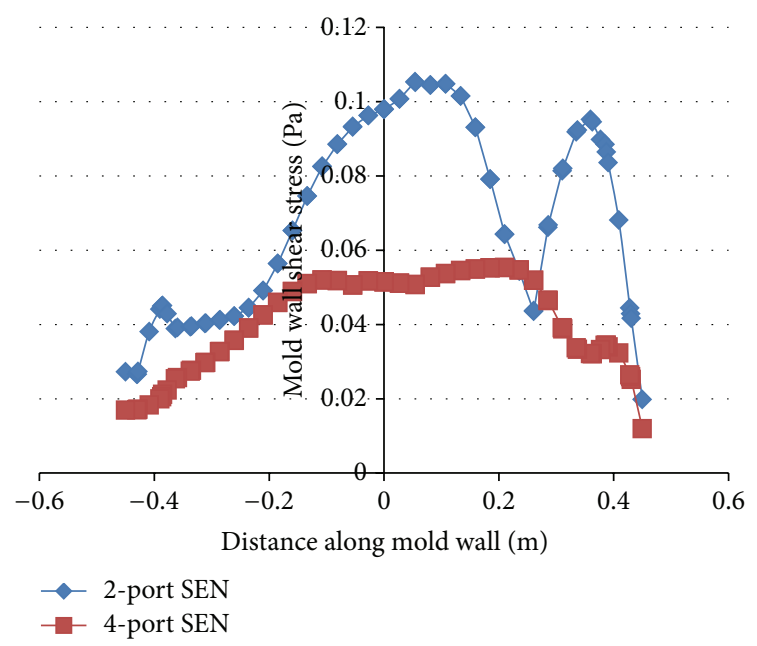

FIgURE 5: Typical shear stress curve along the mold wall for 2-port and 4-port nozzle.

that deviate from the steady state and interaction; its mechanism is more complex. To prevent such accidents, people have done a lot of experimental research and take appropriate measures on equipment and technology; however, breakout accident still happened some times. Due to breakout damage of equipment takes place. Not only that liquid steel loss from tundish as well as from ladle. Beside this, it takes several hours to restart the continuous casting machine which ultimately hamper the production and decrease the yield of the caster.

A typical shear stress curve has been plotted along the side wall of mold for 2-port and 4-port nozzle which is shown in Figure 5. The shear stress is generated due to interaction of high speed incoming fluid from submerged entry nozzle to the side wall of the mold. The shear stress is much more for case of 2-port nozzle as compared to 4-port submerged entry nozzle. This signifies that the susceptibility of breakout for 2port nozzle will be more than 4-port nozzle as it will thin the solidified layer much more as compared to 4-port submerged entry nozzle. 


\section{Conclusions}

The following conclusions can be drawn from the above study of the simulation.

(i) The 4-port nozzle is unique in design and the fluid ejected from the bifurcated port has less velocity as compared to 2-port submerged entry nozzle. It will indirectly help to create less turbulence within the mold.

(ii) The opening of slag eye for 4-port nozzle is nil. But for 2-port nozzle, some area was exposed to environment due to slag opening. It has detrimental effect on product quality due to generation of more inclusion within the cast structure.

(iii) The surface fluctuation is more for 2-port SEN where surface fluctuation is almost nil for 4-port submerged entry nozzle. It means that chances of entrainment of slag particles to the melt are less for 4-port SEN.

(iv) Shell thinning will be less for 4-port nozzle. So chances of breakout will be less for 4-port SEN.

\section{References}

[1] D. F. Wu and S. S. Cheng, "Effect of SEN design on surface fluctuation and solidifying shell in slab mold and its optimization," Acta Metallurgica Sinica (English Letters), vol. 21, no. 5, pp. 341350, 2008.

[2] X.-G. Zhang, W.-X. Zhang, J.-Z. Jin, and J. W. Evans, "Flow of steel in mold region during continuous casting," Journal of Iron and Steel Research International, vol. 14, no. 2, pp. 30-41, 2007.

[3] C.-B. Ji, J.-S. Li, S.-F. Yang, and L.-Y. Sun, "Large eddy simulation of turbulent fluid flow in liquid metal of continuous casting," Journal of Iron and Steel Research, International, vol. 20, no. 1, pp. 34-39, 2012.

[4] X. K. Lan and J. M. Khodadadi, "Fluid flow, heat transfer and solidification in the mold of continuous casters during ladle change," International Journal of Heat and Mass Transfer, vol. 44, no. 5, pp. 953-965, 2001.

[5] R. Kumar Das and S. Kumar Dash, "Free-surface fluctuations for design of submerged-entry nozzle," International Journal on Theoretical and Applied Research in Mechanical Engineering, vol. 1, no. 2, pp. 109-114, 2012.

[6] Y. Haiqi, W. Baofeng, L. Huiqin, and L. Jianchao, "Influence of electromagnetic brake on flow field of liquid steel in the slab continuous casting mold," Journal of Materials Processing Technology, vol. 202, no. 1-3, pp. 179-187, 2008.

[7] W. Zhang, J. Gao, P. K. Rohatgi, H. Zhao, and Y. Li, "Effect of the depth of the submerged entry nozzle in the mold on heat, flow and solution transport in double-stream-pouring continuous casting," Journal of Materials Processing Technology, vol. 209, no. 15-16, pp. 5536-5544, 2009.

[8] X. Miao, K. Timmel, D. Lucas, Z. Ren, S. Eckert, and G. Gerbeth, "Effect of an electromagnetic brake on the turbulent melt flow in a continuous-casting mold," Metallurgical and Materials Transactions B, vol. 43, pp. 954-972, 2012. 

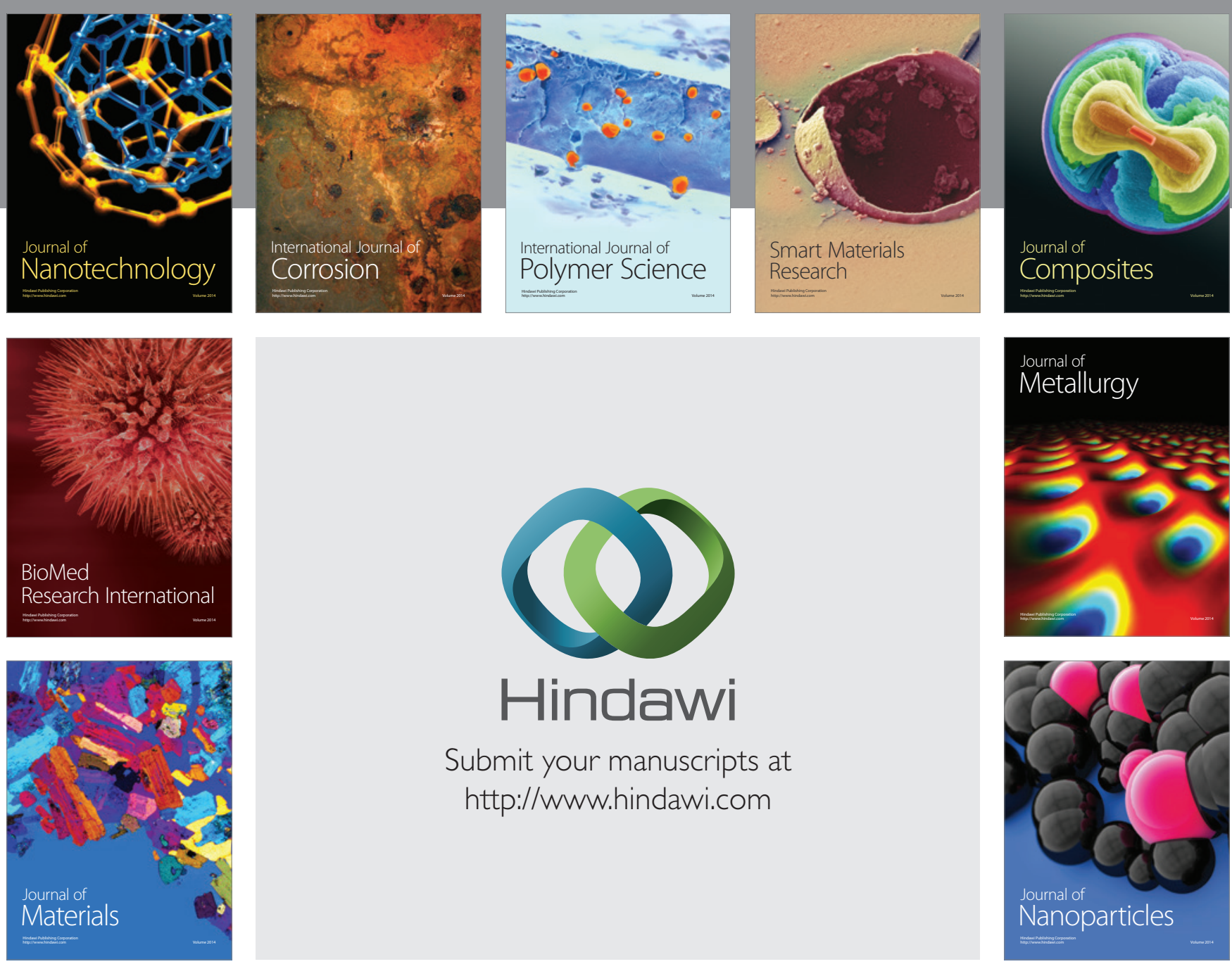

Submit your manuscripts at http://www.hindawi.com
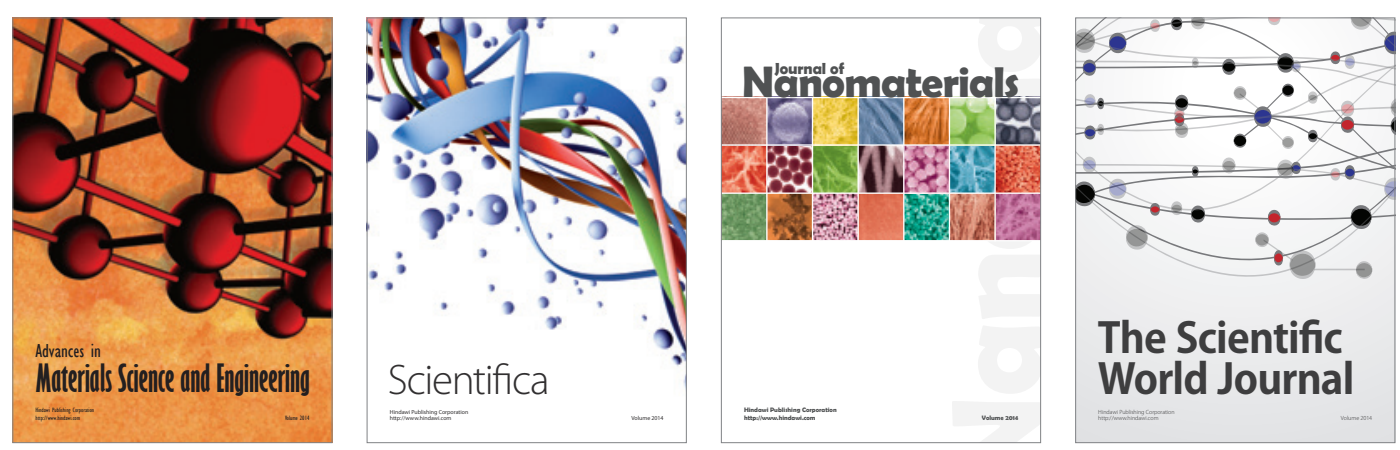

\section{The Scientific World Journal}
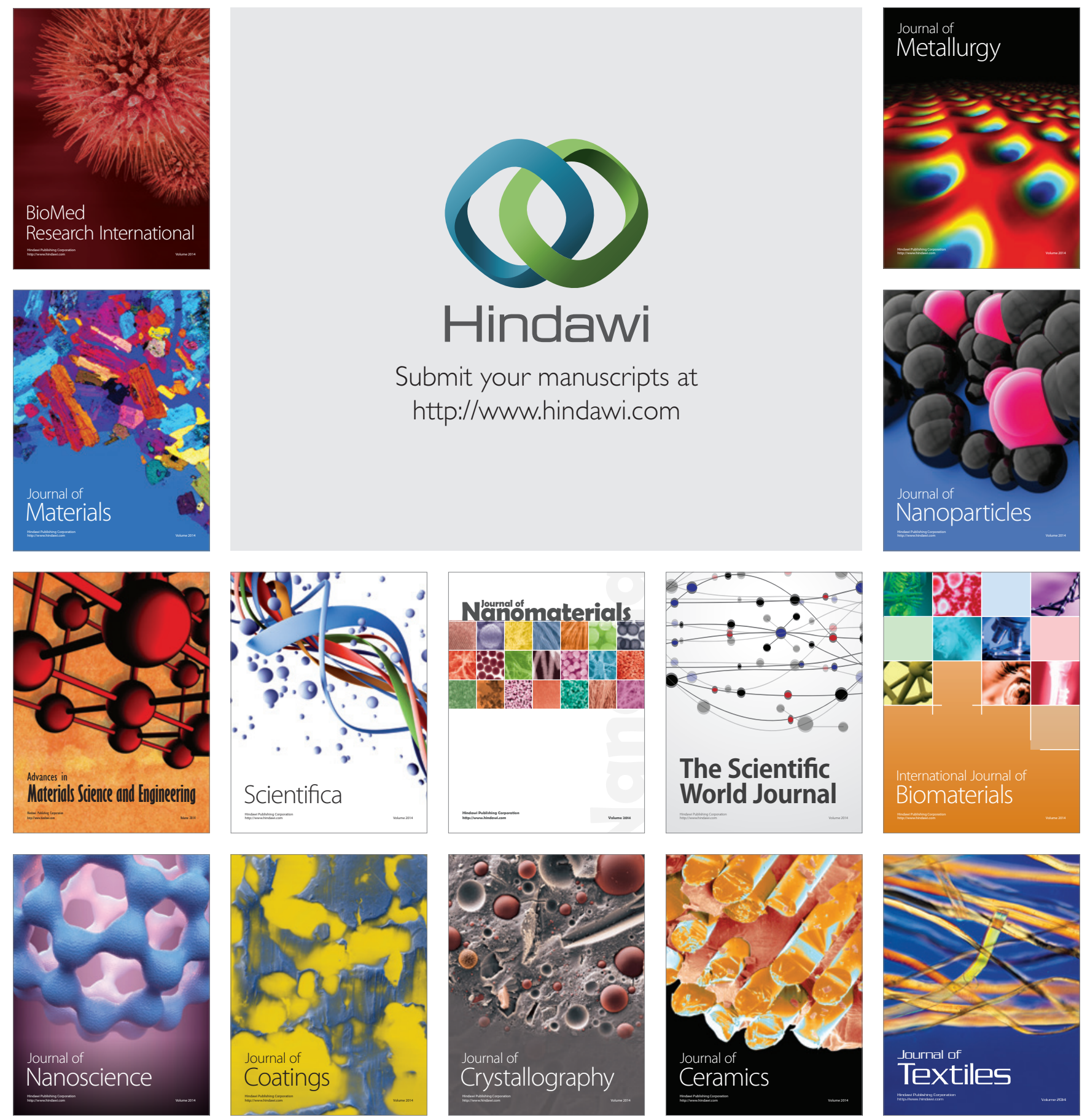